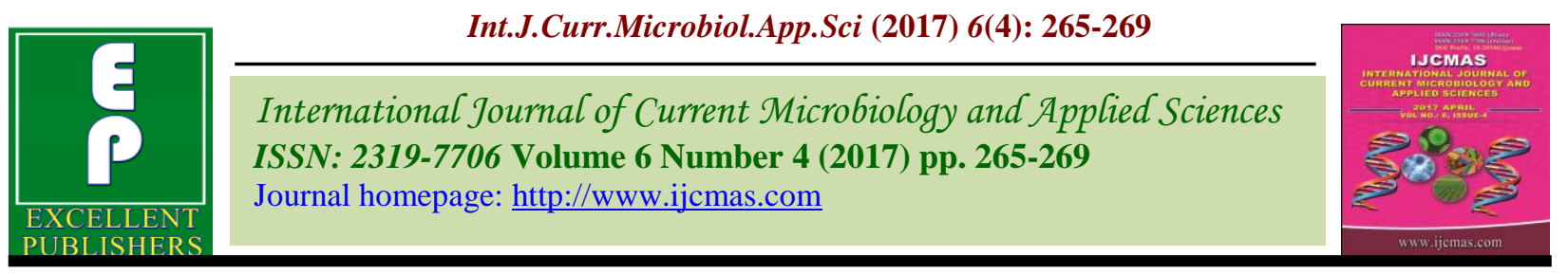

Original Research Article https://doi.org/10.20546/ijcmas.2017.604.030

\title{
A Study of Thyroid Swellings and Correlation between FNAC and Histopathology Results
}

\author{
K. Vijaya ${ }^{1}$, R. Shyamala ${ }^{2}$ and A. Durga Prasad ${ }^{3}$ \\ ${ }^{1}$ Department of Pathology, Mallareddy Medical College for Women, \\ Hyderabad, Telangana, India \\ ${ }^{2}$ Department of Microbiology, Mallareddy Medical College for Women, \\ Hyderabad, Telangana, India \\ ${ }^{3}$ Department of Anaesthesia, Mallareddy Medical College for Women, \\ Hyderabad, Telangana, India \\ *Corresponding author
}

\section{A B S T R A C T}

\section{Keywords}

Thyroid swelling,

FNAC,

Histopathology.

Article Info

Accepted:

02 March 2017

Available Online:

10 April 2017
Thyroid swellings are prevalent in the Indian population and are seen in about 4-7\% of them. They are common in women and their incidence increases with age, exposure to radiation and intake of goitrogens. These swellings cause cosmetic deformity and also produce pressure symptoms due to their location and size. They are viewed with suspicion as the incidence of cancer is high. FNAC of thyroid is a sensitive, easy, cost effective, and a reliable screening test for evaluating these lesions. FNAC helps in differentiating benign from malignant lesions and is very helpful in deciding surgery and follow up of these cases. In this retrospective study FNAC results of 120 thyroid lesions were analysed and correlated with histopathology findings of the excised specimens. The objective of this study is to correlate the results of FNAC and histopathology of thyroid lesions, and assess the role of FNAC in diagnosing thyroid swellings. FNAC is a safe, accurate method with high sensitivity specificity.

\section{Introduction}

Thyroid swellings are frequent cause for anxiety in patients as well as clinicians and proper accurate diagnosis is essential for their management. They cause cosmetic deformity, pressure symptoms related to trachea, esophagus and blood vessels. Fine needle aspiration is a popular, safe, accurate diagnostic method accepted worldwide for diagnosing thyroid swellings. It's limitations include false negative results and rarely false positive results. In a study of Thyroid swellings by Bloch, comparing FNAC and Histopathology results, the accuracy of FNAC was found to be $91.6 \%$ Bloch (1997). In a similar study by Mundasad et al., (2006) the sensitivity of FNAC was found to be $(52.6 \%)$ and specificity $(82.2 \%)$ and accuracy $(79.1 \%)$ for thyroid malignancies. In a study by Handa et al., (2008) on thyroid swellings, the sensitivity and specificity of FNAC was $97 \%$ and $100 \%$ respectively. 


\section{Materials and Methods}

All patients with clinically diagnosed thyroid nodules were included in this retrospective study. This study was included 120 patients who presented to Mallareddy medical college for women, Hyderabad between June 2014 and December 2016. These patients were examined clinically, the size of the swelling, surface, consistency and mobility with deglutition and presence of tenderness were noted. All these patients were analysed by ultrasonography of thyroid swelling, and thyroid hormone profile was done.

FNAC was performed using 23 gauge needle, and smears were fixed in 95\% alcohol, stained with $\mathrm{H}$ and $\mathrm{E}$, and PAP stains. The criteria used for adequacy of specimens as suggested by Kini et al., (1996) and included 6 to8 fragments of well preserved follicular epithelium on each of 2 slides. Adequate smears were screened and results were recorded. Thyroidectomy specimens of these patients, either partial or total were evaluated by histopathological examination. They were processed in automated machines and stained using $\mathrm{H}$ and $\mathrm{E}$ stain.

\section{Results and Discussion}

Out of 120 FNACs studied, 3 were inadequate to report, 109 were benign, 8 cases were malignant. These lesions occurred more commonly in the females, (94 cases, $78.3 \%$ ) than males (26 cases, $21.7 \%$ ), and the female to male ratio is 3.6:1. The peak age of incidence was observed in second and third decade of life. In a similar study by Bhansali the female to male ratio was 2.3: 1 and peak incidence was found in fifth decade of life (Bhansali et al., 1982).

Bethesda system sponsored by National Cancer Institute on October 2007, at Bethesda includes reporting thyroid lesions under six categories (Table 3).

Histopathology was done for 96 lesions, and they were diagnosed as Colloid goiter in 69 cases, Hashimoto's thyroiditis in 2 cases, Follicular adenoma in 14 cases, Follicular carcinoma in 6 cases and Papillary carcinoma in 2 cases. Colloid goiter was the most common lesion (63\%), followed by follicular adenoma (13\%), follicular carcinoma (5\%), papillary carcinoma (1.5\%), hashimoto's thyroiditis $(7.5 \%)$.

Table.1 Incidence of thyroid lesions in age groups

\begin{tabular}{|ll|}
\hline Age & Incidence \\
\hline \hline$<10$ & 02 \\
$11-20$ & 10 \\
$21-30$ & 22 \\
$31-40$ & 34 \\
$41-50$ & 19 \\
$51-60$ & 21 \\
$61-70$ & 12 \\
Total & 120 \\
\hline
\end{tabular}

Table.2 Incidence of the types of thyroid lesions according to FNAC 


\begin{tabular}{|l|c|}
\hline Diagnosis & No of cases \\
\hline Colloid goiter & 70 \\
\hline $\begin{array}{l}\text { Colloid goiter with cystic } \\
\text { degeneration }\end{array}$ & 06 \\
\hline Follicular neoplasm & 16 \\
\hline Hashimotos thyroiditis & 9 \\
\hline Carcinoma thyroid & 8 \\
\hline
\end{tabular}

Table.3 Bethesda system for diagnosis of thyroid lesions

\begin{tabular}{|lcc|}
\hline lesion & no & $\%$ \\
\hline Inadequate & 03 & 2.5 \\
\hline Benign & 109 & 90.8 \\
\hline Suspicious & 0 & \\
\hline Malignancy & 08 & 6.6 \\
\hline
\end{tabular}

Table.4 Incidence of the types of thyroid lesions according to histopathology

\begin{tabular}{|l|l|}
\hline Diagnosis & No of cases \\
\hline Colloid goiter & 69 \\
\hline Follicular adenoma & 14 \\
\hline Hashimotos thyroiditis & 02 \\
\hline Follicular carcinoma & 08 \\
\hline Papillary Carcinoma & 03 \\
\hline
\end{tabular}

Table.5 Positive correlation of result of FNAC with the result of histopathology of the different types of Thyroid lesions

\begin{tabular}{lccccc}
\hline $\begin{array}{l}\text { Type of thyroid lesion } \\
\text { diagnosed by FNAC }\end{array}$ & $\begin{array}{c}\text { NO of cytological } \\
\text { diagnosis }\end{array}$ & \multicolumn{5}{c}{$\begin{array}{c}\text { Correlation with } \\
\text { Histopathology }\end{array}$} & $\begin{array}{c}\text { Diagnostic } \\
\text { Accuracy }\end{array}$ & $\begin{array}{c}\text { Histopathological diagnosis } \\
\text { in fal se cytodiagnosis }\end{array}$ \\
\hline $\begin{array}{l}\text { cytodiagnosis } \\
\text { Correct }\end{array}$ & False \\
\hline $\begin{array}{l}\text { Halloid goiter } \\
\text { thyroiditis }\end{array}$ & 70 & 69 & 1 & 98.5 & Papilary CA \\
$\begin{array}{l}\text { Follicular } \\
\text { Adenoma }\end{array}$ & 02 & 02 & - & & Follicular CA \\
$\begin{array}{l}\text { Follicular } \\
\text { Carcinoma }\end{array}$ & 16 & 14 & 02 & 88.8 & \\
$\begin{array}{l}\text { Papillary } \\
\text { Carcinoma }\end{array}$ & 06 & 06 & - & & \\
\hline
\end{tabular}

Fig.1 Photomicrograph showing cytology of follicular adenoma. pap stain x100 


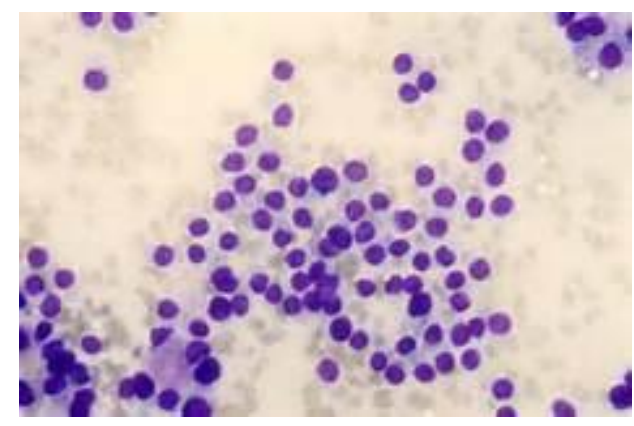

Fig.2 Photomicrograph of cytology of papillary carcinoma. Pap stain x100

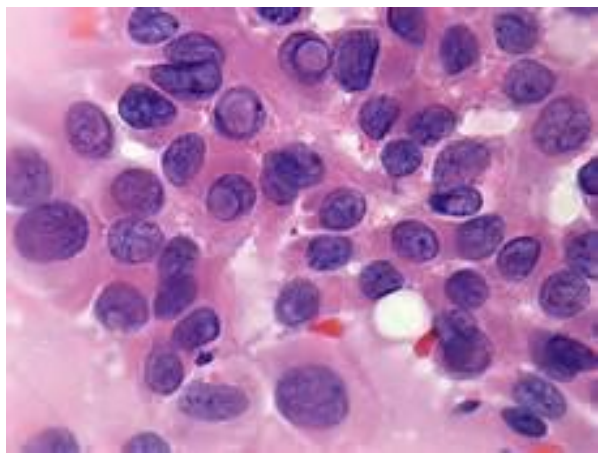

Out of the 96 cases which underwent thyroid surgery, 93 showed positive correlation between FNAC and histopathology. It differed in three cases where the histopathology was different from FNAC results. The diagnostic accuracy of FNAC for thyroid lesions in our study was $93.65 \%$ and specificity was $100 \%$. This is similar to study by Rout et al., (96.05\%), and Altavilla and Pascale (1990) (92.86\%). The accuracy of FNAC analysis is about $95 \%$ in Differentiating benign from malignant nodules of thyroid (Gharib et al., 1994).

In our study follicular carcinoma constituted $72.7 \%$ of cases whereas papillary carcinoma was seen in $27.3 \%$. Table 5 shows the statistical correlation between cytological and histological diagnosis in these patients. There was a discrepancy noted in the diagnosis in 3 cases. One case of nodular goiter on FNAC was diagnosed as papillary carcinoma and two cases diagnosed as follicular adenoma turned to be follicular carcinoma on histopathology. All the 8 cases of malignancy were diagnosed correctly on FNAC as they were reported same on histopathology.

The diagnostic accuracy of FNAC in this study is $93.65 \%$, sensitivity is $78.5 \%$, specificity of $100 \%$ and our findings are similar to the observations of Frable et al., (1979) and reported the diagnostic accuracy of FNAC as 94\%. Pitfalls in FNAC as mentioned by Shaha et al., (2000) are regarding the adequacy of the specimen, accurate sampling technique, and overlapping cytological features between benign and malignant follicular and hurthle cell lesions and, differentiating lymphocytic thyroiditis from lymphoma.

In conclusion the results of our study are comparable to current published data. FNAC is an accurate, simple and safe diagnostic modality for investigating thyroid swellings 
and has high accuracy and specificity. It is of immense value in diagnosis of benign lesions like colloid goiter, hashimotos thyroiditis, and malignancies. It is a useful preoperative tool especially in developing countries like India. (Rout et al., 2011) Surgical resection and histopathological examination is required for indeterminate or suspicious lesions.

\section{References}

Altavilla, G., Pascale, M. 1990. Fine needle aspiration biopsy and diagnosis of thyroid gland diseases, Acta Cytologica, 34: 251-256.

Bhansali, S.K. 1982. Fine needle aspiration versus frozen section diagnosis. Arch. Otolaryngol. Head Neck. Surg., 112: 867-869.

Bloch, M. 1997. Fine needle aspiration biopsy of head and neck masses. Otolaryngol. Head Neck Surg., 89: 62-68.

Frable, W.J., Frable, M.A.S. 1979. Thin needle aspiration biopsy: the diagnosis of head and neck tumors revisited.
Otolaryngol. Pol., 43: 1541-1548

Gharib, H. 1994. Fine needle aspiration biopsy of thyroid nodules: advantages, limitations and effects. Mayo Clin. Proc: 69: 44-49.

Handa, U., Garg, S., Mohan, H. 2008. Role of fine needle aspiration cytology in diagnosis and management of thyroid lesion. Indian J. Pediatr., 25(1): 13-17.

Kini, S.R. 1996. Guides to clinical aspiration biopsy 2nd edition. New York NY, Thyroid, 176-188

Mundasad, B., Mcallidter, I., Carson, J. 2006. Accuracy of fine needle aspiration cytology in diagnosis of thyroid swelling. Int. J. Endocrinol., 2(2): 2325.

Rout, K., Ray, S.K., Biswal. 2011. A Comparative study of FNAC and Histopathology of Thyroid swellings. Indian J. Otolaryngol. Head Neck Surg., 63(4): 370-372.

Shaha A.R. 2000. Controversies in the management of Thyroid nodule. Laryngoscope, 10: 183-193.

\section{How to cite this article:}

Vijaya, K., R. Shyamala and Durga Prasad, A. 2017. A Study of Thyroid Swellings and Correlation between FNAC and Histopathology Results. Int.J.Curr.Microbiol.App.Sci. 6(4): 265-269. doi: https://doi.org/10.20546/ijcmas.2017.604.030 